\title{
CRUISING FOR TRUCKERS ON HIGHWAYS AND THE INTERNET: SEXUAL NETWORKS AND INFECTION RISK
}

\author{
Yorghos Apostolopoulos, Sevil Sönmez, Mona Shattell, \\ Jennie Kronenfeld, Donna Smith, and Sarah Stanton
}

\begin{abstract}
Empirical evidence on the heterosexual partnerships of long-haul truckers suggests connections among occupational stressors, substance misuse, structural factors, and risk for sexually transmitted infections and HIV. Yet the potential risks associated with same-sex partnerships of truckers and truckchasers (men who specifically cruise for truckers) remain largely unknown. Drawing from diverse sources as well as primary and secondary data from 173 truckers and "truckchasers," we discuss how trucking and cruising contexts, in conjunction with Internet fora, jointly create a risk-enabling environment for truckers and their sex contacts. Findings point toward an elusive but extensive sexual network that spans across the Internet and highways and takes advantage of truckers' mobility as it bridges disparate epidemiological spaces and populations. The delineation of cruising within the hypermasculine occupational sector of trucking adds new insights to the study of sexual health, which is particularly important considering the riskladen sex contacts of truckers and truckchasers and potential for infection spread.
\end{abstract}

Long-haul truckers often play a central role in multimodal sex and drug networks that span across the U.S. driving landscape. The multiple and intertwined risk channels that characterize such networks are likely culprits in the potential spread of infectious pathogens (Apostolopoulos \& Sönmez, 2007). Within sexual networks, truckers' heterosexual partnerships are vulnerable to risks from HIV and other sexually transmitted infections (STIs) by virtue of their links to substance misuse, occupational stressors, sex partner concurrency, spatial attributes of trucking contexts,

Yorghos Apostolopoulos, PhD, is Associate Professor with the Department of Public Health Education, School of Health and Human Performance, University of North Carolina Greensboro, Greensboro NC and Division of Infectious Diseases, Emory University School of Medicine, Atlanta, GA. Sevil Sönmez, $\mathrm{PhD}$, is Professor with the School of Health and Human Performance, University of North Carolina Greensboro, Greensboro, NC. Mona Shattell, PhD, RN, is Associate Professor with the School of Nursing, University of North Carolina Greensboro, Greensboro, NC. Jennie Kronenfeld, PhD, is Professor with the School of Social and Family Dynamics, College of Liberal Arts and Sciences, Arizona State University, Tempe, AZ. Donna Smith, PhD candidate is a Researcher with the Institute of Public Health, College of Health and Human Sciences, Georgia State University, Atlanta, GA. Sarah Stanton, MPH, is Health Programming Coordinator with the Atlanta Lesbian Health Initiative, Atlanta, GA.

This study was supported by funding from the U.S. National Institutes of Health (R01-HD042972) and Arizona State University.

Correspondence should be addressed to: Dr. Yorghos Apostolopoulos, Department of PHE, School of HHP, University of North Carolina Greensboro, PO Box 26170, Greensboro, NC 27402-6170, y_aposto@uncg.edu 
and broader social and structural influences (Apostolopoulos \& Sönmez, 2006). Given the hypermasculine subculture of the trucking sector along with the growing role of the Internet in sex partnering, the understudied same-sex encounters of truckers represent considerable sociological and epidemiological interest (Apostolopoulos et al., 2010).

In this article, we present how interstate highways, trucking settings, and intersecting physical and virtual cruising milieux converge to create STI/HIV risk-enabling environments primarily for male truckers and their male sex contacts, and secondarily for the female partners of straight-identified and bisexual truckers. Drawing from social constructionist theoretical perspectives that acknowledge discontinuities between sexual identities and practice (Delamater \& Hyde 1998), we discuss how these risk environments function as a sexual marketplace and, further, how a system of conduits with multiple, complex, and intertwined risk channels render MSM trucking populations highly vulnerable to infection risks.

\section{SPACE AND THE SEXUAL HEALTH OF MEN WHO HAVE SEX WITH MEN}

In recent years, rising STI/HIV prevalence among men who have sex with men (MSM) has been attributed to increases in unprotected anal intercourse (UAI) engaged in at both commercial, public sex venues (PSVs) and noncommercial, public sex environments (PSEs), growing use of club drugs, and the emerging role of Internet sex seeking (Centers for Disease Control and Prevention [CDC], 2003a; Junge, 2002; Somlai et al. 2001). A host of factors, such as sensation seeking, sexual compulsivity, depression, lack of social support, need for intimacy, cognitive escape, HIV fatigue, and failure of HIV prevention messages has emerged as foremost contributors to the STI/HIV spikes (e.g., Adam, Sears, \& Schellenberg, 2000; Diaz, Ayala, Bein, Henne, \& Marin, 2001; Mansergh et al., 2002; McKirnan, Vanable, Ostrow, 2001).

The very space in which MSM seek partners and where sexual acts unfold is a detriment to the practice of safer sex, as contextual variations have the potential to exacerbate or diminish the impact of risk factors (Parsons \& Halkitis, 2002). PSVs include adult book/video stores or arcades, gay bars, backrooms of bars/clubs, bathhouses, circuit parties, and pornographic theaters, whereas PSEs include public toilets (or T-rooms), parks/picnic areas, alleys and parking lots, beaches, and docks. Whereas PSVs offer opportunities for exposure to HIV/STI prevention messages, PSEs rarely (if ever) do and therefore represent greater risk-in fact, sex transactions at PSEs have been consistently linked with higher STI/HIV risk taking (Flowers, Marriott, \& Hart, 2000).

PSEs are typically "zoned" for three types of activity— "waiting," "meeting," and "playing" (Huber \& Kleinplatz 2002), with sexual activity linked to the third zone. Although sex occurs in a "semipublic" space, distance from open areas, vegetation, or bathroom stalls often seclude the activity. Oral sex is the most prevalent form of sexual exchange; however, anal sex also occurs, albeit less often owing to anatomical or logistic considerations. Although the likelihood of HIV transmission via oral sex is significantly low, chances for other STIs remain high (CDC, 2003b). The use of "poppers" to aid rapid sexual performance during anal intercourse, and crystal meth to initiate, enhance, and prolong sexual encounters has been on the rise (Halkitis, Parsons, \& Stirratt, 2001). MSM with HIV-positive MSM are more likely than their HIV- counterparts to cruise at PSEs (Binson et al., 2001). 
Beyond known physical contexts, the Internet has become the new frontier for MSM because it facilitates multiple opportunities for cruising and sexual encounters (e.g., Rebchook, Curotto, \& Kegeles, 2003; Rietmeijer, Bull, McFarlane, Patnaik, \& Douglas, 2003). MSM cyber-sites are sexualized places where men express in graphic detail the type of sex acts and partners they are seeking. This may be partially explained by the fact that virtual communication has a "disinhibiting" effect that allows men to articulate what they seek in a manner they may be unable to do so face-to-face (McLelland, 2002). The Internet also affords users opportunities to initiate contact with persons from epidemiologically and geographically disparate regions they would otherwise never meet (McLelland, 2002). Risks associated with Internet sex seeking have been confirmed by a number of researchers: Internet sex seekers reveal more partners and higher UAI rates than non-Internet sex seekers (Chiasson et al., 2003; Rebchook et al., 2002), they are more likely to report UAI with nonmonogamous partners and those of unknown serostatus (Perdue, Thiede, Valleroy, \& Mackellar, 2001), they are more likely to be MSM, report higher STI rates, have greater sexual exposure to HIV-positive partners (McFarlane, Bull, \& Rietmeijer, 2000), and they are more likely to be MSM whose sexual risk taking is linked to cybersex compulsivity (Cooper, 2002). In addition, $75 \%$ of Internet sex seekers report engaging in group sex (Mettey, Crosby, DiClemente, \& Holtgrave, 2003). Finally, the growing number of Web sites that eroticize barebacking may be partially responsible for the increase in its acceptability among MSM and may be linked to subsequent STI/HIV ramifications (Halkitis \& Parsons 2003).

\section{TRUCKING MILIEUX, NETWORKS, AND STI/HIV RISK}

Research evidence demonstrates that American and Canadian truckers oftentimes engage in risk-laden sexual mixing and drug exchanges on the road (Apostolopoulos \& Sönmez, 2007; Lichtenstein, Hoole, Grimley, St. Lawrence, \& Bachmann, 2008; Stratford, Ellerbrook, Akins, \& Hall, 2000). Recent investigations have gone a step further by ascertaining whether such behavioral patterns render truckers and their risk contacts vulnerable to actual STI/HIV infection (Apostolopoulos et al., 2010; Valway, Jenison, Keller, Vega-Hernandez, \& Hubbard McCree, 2009). In fact, truckers recruited from trucking settings in Georgia and New Mexico tested positive for hepatitis C $(10 \%, 8.5 \%)$, hepatitis $\mathrm{B}(1.7 \%)$, and hepatitis B core antibody $(10.4 \%)$, chlamydia $(1.7 \%, 1.3 \%)$, gonorrhea $(0.2 \%$; New Mexico only), syphilis $(3.3 \%, 0.2 \%)$, and $\operatorname{HIV}(3.3 \%, 0.2 \%)$, respectively.

Ethnoepidemiological research on truckers' risk exposures has also brought to the fore a gamut of loosely linked populations, which revolve around the trucker and which are defined based on truckers' roles within a social geography of risk (Apostolopoulos \& Sönmez, 2007). Key among these groups are truckers; female sex workers; "truckchasers" (or "goodbuddies"), who are men who cruise truckers; drug suppliers and pimps; polishers (transient homeless persons who buff and polish chrome details of trucks) and lumpers (individuals who load and unload trucks); employees of trucking and shipping companies and truck stops; and spouses, partners, lovers of truckers as well as any other sexual partners.

The social, sex, and drug interactions among truckers and the foregoing populations are embedded within diverse, risk-enabling milieux with conjoined but distinct topographies and sexual cultures (Apostolopoulos et al., 2010). Physical contexts for interactions include truck stops, highway rest and picnic areas, weigh and fuel 
stations, loading docks at trucking terminals, and various legitimate (e.g., lodging) as well as dubious off-road establishments (e.g., adult entertainment) that cater to truckers. Unprecedented access to the Internet from trucking terminals, truck stops, and truck cabs has provided truckers with a unique medium for sex seeking and has pointed them toward a simultaneously public and private cyberspace for limitless sex partnering (Apostolopoulos et al., 2003). Virtual "hookups" offer truckers, truckchasers, and other men and women opportunities to arrange subsequent in-person meetings enabled largely by truckers' wide-ranging mobility (Apostolopoulos et al., 2007). There is evidence that Internet-dating MSM report higher methamphetamine use, more sexual partners, and higher UAI rates than non-Internet-using MSM (Horvath, Bowen, \& Williams, 2006), which underscores the potentially grave role of virtual cruising in the context of trucking. Although heterosexual risk exchanges are initiated and occur at actual trucking settings, same-sex interactions unfold predominantly at highway rest areas and are facilitated by the $\mathrm{CB}$ radio and the Internet (Apostolopoulos et al., 2007).

\section{DATA AND METHODS}

\section{SETTINGS, POPULATIONS, AND PROCEDURES}

Data reported here come from two multimethod, sequential studies on truckers' STI/HIV risks. The studies were approved by the institutional review boards of Arizona State University and Emory University, and all possible efforts were made to protect the privacy and confidentiality of study participants. Because of the elusive nature of MSM trucker populations, respondent-driven sampling procedures (Heckathorn, 1997) were used to recruit truckers and truckchasers for several forms of data collection. Triangulated procedures not only provide a comprehensive mapping of trucker STI/BBI (blood-borne infection) risks but also increase confidence in validity and boost generalizability of findings to trucking populations.

Formative Evaluation of STI/HIV Risk Among Truckers. Ethnographic data were collected from truckers and their social and risk contacts recruited from urban and rural truck stops in Arizona (Apostolopoulos et al., 2007; Apostolopoulos \& Sönmez, 2006). Following an interview lead, members of our research team attended the Bobtail Convention of gay/bisexual truckers and truckchasers in Oklahoma, where we conducted two focus groups involving a total of eight individuals and in-depth interviews with seven truckers and truckchasers. Following leads obtained from the convention, telephone interviews were conducted with 14 truckchasers and five gay/ bisexual truckers who were recruited from selected MSM Web sites.

Ethnoepidemiological Research on STI/BBI risk Among Trucker Networks. As part of a large-scale investigation in inner-city Atlanta truck stops, in-depth interviews were conducted with 60 truckers and online focus groups were conducted with five gay/bisexual truckers, two gay and bisexual truckchasers, and one straight-identified truckchaser. In the same vein, telephone interviews were undertaken with seven gay truckers and 11 truckchasers recruited using the Internet. All study participants were encouraged to provide pseudonyms to avoid revealing identifying information. Contextual dimension was added to foregoing data with the inclusion of Internet postings as secondary data, from 53 truckers and truckchasers gathered from chatrooms dedicated to trucker-truckchaser sex. The individual face-to-face interviews were 
TABLE 1. Data collection methods, samples, and research settings

\begin{tabular}{|c|c|c|c|}
\hline Location & Data collection method & Sample & Settings and media \\
\hline \multicolumn{4}{|c|}{$\begin{array}{l}\text { Phase I. Formative work on truckers } \\
\text { and STI/HIV risk }(\mathrm{N} 1=34)\end{array}$} \\
\hline $\begin{array}{l}\text { Fieldwork with MSM in } \\
\text { Oklahoma }\end{array}$ & $\begin{array}{l}\text { - Focus groups } \\
\text { - Personal interviews }\end{array}$ & $\begin{array}{l}\text { - Truckers (MSM), truck- } \\
\text { chasers (N=8) } \\
\text { - Truckers (MSM), truck- } \\
\text { chasers (N=7) }\end{array}$ & $\begin{array}{l}\text { Bobtail Convention } \\
\text { (gay/bisexual truckers, } \\
\text { truckchasers) }\end{array}$ \\
\hline $\begin{array}{l}\text { MSM-targeted research } \\
\text { across state lines }\end{array}$ & - Telephone interviews & $\begin{array}{l}\text { - Truckers (MSM), truck- } \\
\text { chasers }(\mathrm{N}=19)\end{array}$ & Recruited via Internet \\
\hline \multicolumn{4}{|c|}{$\begin{array}{l}\text { Phase II. Ethnoepidemiological research on } \\
\text { trucker risk networks and STI/BBI risk (N2=139) }\end{array}$} \\
\hline $\begin{array}{l}\text { MSM-targeted research } \\
\text { across state lines }\end{array}$ & $\begin{array}{l}\text { - Online focus groups } \\
\text { - Telephone interviews }\end{array}$ & $\begin{array}{l}\text { - Truckers (MSM), } \\
\text { truckchasers }(\mathrm{N}=8) \\
\text { - Truckers (MSM), truck- } \\
\text { chasers }(\mathrm{N}=18)\end{array}$ & $\begin{array}{l}\text { Internet Recruited via } \\
\text { Internet }\end{array}$ \\
\hline $\begin{array}{l}\text { Fieldwork on trucker net- } \\
\text { works in Georgia }\end{array}$ & $\begin{array}{l}\text { - Personal in-depth } \\
\text { interviews }\end{array}$ & - Truckers $(\mathrm{N}=60)$ & Urban truckstops in Atlanta \\
\hline $\begin{array}{l}\text { MSM-targeted research } \\
\text { across state lines (secondary } \\
\text { data) }\end{array}$ & $\begin{array}{l}\text { - MSM trucker-centered } \\
\text { y chatroom postings }\end{array}$ & $\begin{array}{l}\text { - Truckers (MSM), truck- } \\
\text { chasers }(\mathrm{N}=53)\end{array}$ & Internet \\
\hline
\end{tabular}

conducted in locations at and around the selected study sites, which afforded study participants the most privacy (e.g., truck cabs, rest areas, and vacant lots near truck plazas and truck stops as well as hotel/motel rooms in downtown Atlanta along main trucking roads). Online focus groups were conducted on secured university computers by research faculty and graduate students who underwent study-specific training for online data collection. For the face-to-face interviews, field researchers with extensive experience with similar social network research conducted at Emory University were selected. Male interviewers were chosen owing to the potentially risky sites selected for data collection in inner-city Atlanta. These researchers also underwent study-specific training involving mock interviews. Table 1 presents a summary of the data, methods, samples, locations, and settings of the study.

\section{DATA ANALYSIS}

Primary data include: (a) individual background characteristics (e.g., health, trucking and cruising history, sexual and substance-use behaviors); (b) psychosocial factors (e.g., professional pressures, life traumas); (c) network properties (e.g., sexual partnerships, concurrency of sex contacts); (d) spatial domains (e.g., trucker pathways, trucking and cruising milieux); and (e) sociostructural factors (e.g., trucking operations, occupational stressors).

All interviews were transcribed and entered into NVivo for textual analysis. Two research associates with extensive textual data experience, who underwent study-specific training worked with the principal investigator to code and analyze the data.

Preliminary thematic coding was used to establish measures of relationships between truckchasers and truckers within cruising grounds. An open coding approach was used to bracket text sections into themes (Emerson, Fretz, \& Shaw 1995). The nature of the data warranted multilayered coding of text into several themes following the establishment of intercoder reliability and validity (Denzin \& Lincoln, 1994), which was repeated as new coding categories of inquiry emerged. Once preliminary thematic bracketing was completed, data analysis aimed to complete four tasks: (a) 
axial coding and memoing to explore themes and relationships between them for cruising spaces and methods; engagement of MSM trucking populations with these milieux; sexual behaviors of truckers and truckchasers; sexual scripts; relationships and interactions between truckers and truckchasers and their consequences; and sexual identity, homophobia, and trucker image; (b) thick descriptions of cruising grounds for additional details; (c) explanations of how cruising grounds and conditions influence sexual interactions and expose populations to risk; and (d) conceptual mapping to graphically explore relationships among foregoing themes.

\section{RESULTS AND DISCUSSION}

\section{MSM TRUCKER NETWORKS AND THEIR CRUISING MILIEUX}

This investigation has uncovered a loose but distinct MSM trucker network nested within the wider social network of truckers (see Apostolopoulos et al.,). Key populations include (a) straight-identified truckers, who have sex with women and sometimes with men; (b) bisexual truckers, many of whom are married, who have opportunistic sex with men and women on the road; (c) gay truckers, who are frequently "closeted" in their professional circles and who have sex predominantly with non-truckers; (d) truckchasers, who may be straight-identified, gay or bisexual, and cruise primarily for truckers; and (e) drug suppliers.

Truckchasers, who often engage in anonymous sex and other risky behaviors with multiple partners, have a socially constructed invisibility that makes them difficult to identify and reach and thus distinguishes them as a "hidden population." These men, who often differ in occupation, class, race, and geographic region, also share a deep fascination with truckers. Their fetish for truckers often leads them to arrange their lives around opportunities for sexual contact with them. For these men, truckers become sexual objects attributed with masculinity, virility, and manliness. Truckchasers are drawn to the freedom and power they perceive truckers to possess as a result of truckers' lifestyle and the heavy machinery they operate. Truckchasers often see truckers as embodying the "last cowboy" in a modern world and thus epitomizing manhood.

Truckers' and truckchasers' paths intersect at both physical and virtual settings. Physical settings include wooded highway rest areas along highways with public toilets and picnic areas and some truck stops. These "semipublic" settings limit negative social consequences, especially for straight-identified truckers and truckchasers seeking sexual gratification without pressure to continue sexual or social contact, while also offering relatively easy access to multiple and anonymous sex partners (Hollister, 2003). Although the degree to which they facilitate or activate certain psychosocial or physiological mechanisms remains unclear, such PSEs have been linked with recreational drug use in conjunction with risky sex-which are attributable, among others, to depression, cognitive escape, sexual sensation seeking and adventurism (Kippax \& Crawford, 1993). Particularly for straight-identified truckers and bisexual truckchasers, who potentially bridge male and female sex partners, and in an environment typified by anonymous sex, the implications of foregoing factors for infection spread are quite significant. Alternatively, virtual settings include MSM Web sites, social network sites, listservs, chat rooms, and bulletin boards that cater specifically to truckers and truckchasers. These diverse fora connect men interested in hook-ups with anonymous sex partners who happen to be truckers or truckchasers. Some sites post the "dos and don'ts" of truckchasing, list best locations for 
cruising by state and highway, and give opportunities to visitors to post their personal ads or driving schedules. Online personal advertisements include information such as type of sex the men are seeking, and their marital status, their serostatus and are embellished by nude/seminude photographs. Two personal postings illustrate the foregoing:

I'm in the [city] and want some hot TOP truckers that are passing through, who want to unload in my holes ... oral, anal, kinky, daddy types, sex in the cab or sleazy motels all A+...Raw is best if you're neg... I'm off I-12 exit [\#], my email is [e-mail address] . .. Here is a link to a g-pic of me [Web link]" (truckchaser posting)

I'm a straight married man, 45, 6'3", 195 lbs traveling the 48 states as a self-employed trucker... I'm seeking guys to fuck up the ass and to suck my massive cock (trucker posting)

Although conventional cruising methods are successfully employed by truckchasers at actual physical locations (Apostolopoulos et al., in press), the Internet has facilitated MSM sexual networks to proliferate in cyberspace and has taken truckchasing to new heights. The Internet has given form to a previously highly diffused trucker network of MSM by making it possible for the men to remain anonymous via chatroom aliases while disseminating explicit postings. Consequently, hookups arranged online have led to unprecedented increases in sexual encounters between truckchasers and truckers along highways.

\section{SEX BETWEEN TRUCKERS AND TRUCKCHASERS}

Truckers as sexual objects. A recurrent theme to emerge from interviews with truckchasers is one of confirmation of truckers' stereotypical masculinity. Truckers are viewed as projecting the ultramasculine image popularized by the iconic Marlboro man-in this case, the "modern cowboy" who traverses the country alone on his 18 -wheeler. The element of risk and mystery attached to this image further enhances the attraction of truckers, because their perpetual movement makes them appear elusive at the same time that they are perceived as "easy to get because they are mostly alone and in need of sexual release."

It's the Village People myth, it's the Marlboro man, there's a freedom to it . . . the last of the modern day cowboys... It's mythological. (truckchaser, 57)

Interviewer: What kind of image does "the trucker" have for you?

Truckchaser: Masculine, blue-collar worker, loner, lonely, horny, easy to get.

Interviewer: What type of trucker are you most attracted to?

Truckchaser: Masculine, slightly overweight to overweight, bearded or facial hair, and hairy body. (truckchaser, 53)

The trucker's masculinity is symbolized by various tangible signs such as physical characteristics (e.g., heavy-set, hairy), typical style of dress (e.g., flannel shirt, work boots), and behaviors (e.g., "straight-acting") that represent the opposite of conventional images of femininity. For truckchasers, men who convey effeminate qualitieswhich are attributed by default, if any or all of the foregoing are absent—or who try to emulate masculinity are deemed undesirable. As a result, there is a powerful draw to "bear" types who embody masculinity. 
You start looking at "bears" as the masculine big hairy types and associating masculinity with hair, blue collar, heavy machinery-anything that you can think of that would entail masculinity would be usually associated with trucking ... Of course, a lot of men's fantasies is having a "bear" .. . muscled . . well-hung trucker. (truckchaser, 34)

In the minds of many, the coveted aura of masculinity is inextricably linked to "straightness," which in turn is typically associated with married men. As a result, truckchasers are often drawn to married or bisexual truckers; on the other hand, straight-identified truckers prefer "straight-looking" and "straight-acting" truckchasers as partners because the relationships can be easily camouflaged as "guys just hanging out together.”

I've formed a close relationship and strong friendships with eight married drivers . . . have met their spouses and children and have visited their homes . . . I play it very straight in their territory. (truckchaser, 53)

Sometimes truckers will ask you if you are married because they feel safer having sex with other married men ... I think they feel that they are not having sex with gay men .... so it's going to be okay. (truckchaser, 48)

Questions of sexual identity. Highly complex connections exist between trucking, masculinity, sexual identity, MSM activity, and homophobia. In fact, it is virtually impossible to examine the dynamics of relationships between truckers and truckchasers without touching upon these connections within the occupational context of the trucking sector. Narratives from gay and bisexual truckers suggest that for a trucker to identify as gay is no less than an invitation for trouble. In the hypermasculine world of trucking, homosexuality is often treated with public displays of disdain at best and threats or actual demonstrations of violence at worst-sometimes perpetuated by straight-identified truckers in an effort to protect their public heterosexual image. Truckers' antipathy toward homosexuality is often expressed with startling fervor.

There's a couple of rest areas in Ohio that queer truckers go there ... I'll kill 'em ... I'm a gay basher... I'm straight and want to be left alone... We're the last bastion of rednecks in America. (trucker, 50)

Yeah, my favorite saying is "I hear some good buddy on the radio and I'll tell them: hey, look I got a .357 Magnum you can suck the barrel off . . if you want to while I pull the trigger.” (trucker, 55)

Openly gay truckers are vulnerable to homophobic backlash by fellow truckers. Consequently, most gay truckers remain closeted to shield themselves from risk of being fired, threat of physical harm, police harassment, truck vandalism, and other forms of social, professional, or personal persecution or exclusion. Gay truckers remain sexually active primarily with non-truckers they meet on the road; some even report engaging in periodic sexual encounters with women to minimize social pressure.

It's dangerous for a gay trucker... 'cause they are more than likely to get the shit kicked out of them somewhere along the lines, if somebody else finds out that they are gay. (trucker, 31)

As for truckchasers, many truckers confirm their knowledge of other truckers hooking up with "good buddies" at rest areas, recount personal experiences with being 
approached themselves, vocalize contempt for these sexual activities, or vehemently deny any personal involvement.

I've been offered [sexual services] from both sexes... Several men approached me sexually and got the living hell beat out of them. (trucker, 54)

Went to the restroom and next thing I know he [truckchaser] comes walking in and standing over at the urinal and I was in a stall and he keeps looking at me in the mirror ... I told him 'fella, I want to tell you something: you better go back out there and get back on the radio, do whatever you want to do, 'cause you look at me one more time, I'm gonna gut you like a fish." ... Oh, he zipped his pants up and walked outside, and when I got through and walked outside he was sitting out there looking at me . . But I meant exactly what I said. (trucker, 50)

Interviews confirm the pervasive sexual activity between truckers and truckchasers. To begin to understand the dynamics that shape sexual encounters between truckchasers and straight-identified truckers in particular, greater reflection is required to understand the use of these terms. Not all men who have sex with other men define themselves as gay or bisexual; therefore the term straight-identified truckers helps to contextualize same-sex behaviors in the trucking subculture. For many straightidentified truckers, same-sex behavior does not mean "gay" in any sense consistent with definitions of gay identity - such as getting involved in gay communities and telling others about their same-sex desires, or organizing their social world around these desires and behaviors. Yet it is important to identify truckers who have sex with truckchasers by their rejection of an identity category. Regardless of being a straight-identified gay or bisexual trucker or truckchaser, there are no clear-cut answers to questions regarding sexual identity. The responses that follow indicate the complexity of the issues and the highly individualistic takes on them.

Interviewer: What is your sexual identity?

Truckchaser: Behaviorally gay, internally straight. (truckchaser, 48)

Interviewer: What words would you use to describe your sexual identity?

Truckchaser: Umm ... I think I'm bi ... I was trying to explain to a friend once that we were probably both bi, him leaning more toward women and me toward men . . I'm not real sure where that puts us... It doesn't really put us in bi, it doesn't really put us in gay. (truckchaser, 53)

Established links between non-gay identification and risky sexual practices (Huber \& Kleinplatz, 2002) warrant special attention to be paid to the construct of sexual identity, particularly because individual definitions of sexual identity can impact the extent of risk taking or avoidance. This is demonstrated by several factors: First, straight-identified men often incorrectly associate risk with gay identity rather than same-sex behaviors and as a result do not perceive themselves to be at risk. Second, the compartmentalization of their lives and sexuality can lead these men toward a quest for impersonal sexual encounters as one among few available options, thereby turning anonymous sex into a compelling choice. From our interviews with truckchasers, it becomes evident that some straight-identified truckers rationalize their same-sex behaviors as a physical release that does not threaten their relationships with their female partners, whereas for others, heterosexuality is a type of uniform to wear as needed. 
I thought it was kind of heart-wrenching-these guys would have all sorts of sex with you and then sit there and talk about how much they love their wives and family... It was almost like they were trying to put their heterosexuality back on. (truckchaser, 47)

Truckers enjoy limited social support in their hypermasculine world and also deal with occupation-imposed constraints on the social aspects of their lives, such as limited opportunities for intimacy. Not surprisingly, anonymous sexual encounters that do not require self-explanation offer intimacy to these men without compromising their social identity.

Sexual Encounters. Regardless of their personal involvement, truckers and truckchasers confirm extensive sexual encounters between men that unfold at a range of trucking environments, such as highway rest areas, picnic areas, and roadside adult bookstores and some truck stop toilets with stalls that have "glory holes:"

\begin{abstract}
Most of it [cruising] happens in rest areas, and then you hear it at truck stops too ... I mean they get on the radio and... some guy offers a blowjob or something like that.. . I've seen guys in the rest areas that'll just hang around the bathroom ... or they write on the walls, and leave their phone numbers. (trucker, 33)
\end{abstract}

My first experience was at a truck stop ... had to go to the bathroom and then realized there was "glory holes" there ... Didn't understand what they were there for until, well, something popped through and then I was like "Okay!'” (truckchaser, 39)

Sexual contact is often the end result of intricate cruising methods employed by truckchasers or prearranged Internet-initiated hook-ups between truckchasers and truckers. Encounters initiated by truckchasers cruising along highways often involve straight-identified truckers seeking companionship, quick sexual relief, or some type of intimacy-triggered more by impulse and less by design. Those initiated online, however, are more likely to involve truckers who are more cognizant of their sexual proclivities. Regardless of how they are initiated, the sex is mostly anonymous but differs by location-involving mainly oral sex behind bushes and inside toilet stalls at rest areas, and anal sex inside the truck cab, which offers greater privacy and comfort. Particularly revealing are the rules of engagement, the choreographed nature of the sex act, the lack of communication that characterizes most anonymous contacts, and the effects of all the foregoing on the risks inherent in these encounters (Apostolopoulos et al., 2010).

Strategies and rituals of cruising. Truckchasers have devised strategies that include complex visual and verbal cues to signal their interest to truckers and explore the reciprocity of that interest in a manner that will culminate in mutual satisfaction. Truckchasing etiquette corresponds to different cruising spaces to account for the social contexts and risks involved. Interactions are highly scripted and dictated mostly by nonverbal communication and unarticulated, but mutually understood meanings. Regardless of interest or intention to participate, or sexual identity or desire, truckers and truckchasers know the unspoken language of cruising for sex. Initial contact can vary from loitering in bathrooms, deliberate stares, licking of lips, suggestive rubbing of one's crotch, approaching parked trucks with open doors, repeatedly tapping the car's brake lights at rest areas, and exposing oneself while driving next to a truck to making clicking sounds on the $\mathrm{CB}$ radio to initiate conversation with truckers (and to signal them to move the conversation to other channels). 
You hear the guys at the rest areas... you'll hear them on the radio "BJ [blow job] channel [\#]". . . Apparently it must work... 'cause you hear them all the time at rest areas... They'll sit in the rest area, and if you pull in to use the bathroom, they'll sit in their car and tap their brakes a couple of times... They'll stand right by the bathroom and look you over as you walk in and out of the rest area. (trucker, 47)

The simultaneous presence of multiple truckers and truckchasers at highway rest areas and picnic grounds creates the mental picture of a sexual marketplace, in which those involved in the encounters are well aware of the others' intentions (see Apostolopoulos et al., 2010).

"Pickle Parks" and "Lollipop Heavens." Routine references to highway rest areas by truckers as "lollipop havens" or "pickle parks" imply common knowledge of prevalent sex activity that occurs there. For those who frequent PSEs, sexual pleasure is often amplified by the adrenaline rush brought on by the potential risk of being caught in a public location or getting arrested. Furthermore, the spontaneity of sex with anonymous partners and the promise of multiple sexual encounters in the span of a short time increase the excitement:

It's more sexually exciting . . the risk, the spontaneous, anonymous character of cruising for truckers ... and there's a public element in there... There's always the risk. . . The risk I like is not physical danger but just that the police might arrest me. (truckchaser, 43)

One of my favorite spots is a picnic area north of [city] . . some picnic tables and a chain-link fence with an opening into the wooded area behind... Never have to look for truckers, they know what's there and stop and venture back for a quick one... I'm 56 and have been doing this since I was 26. (truckchaser, 56)

Although public and semipublic spaces represent sexual excitement for some, these locations are among the few available viable options for some truckers seeking samesex encounters, primarily as a result of the stigma that homosexuality carries in the trucking context. This is clearly not the case for openly gay/bisexual men but rather for straight-identified truckers who go to great lengths to remain closeted. It is ironic, then, that those who have more vested in hiding their sexual activities have few choices outside of semipublic venues that carry the greatest potential for discovery.

Sexual "Hit-and-Run." Discussions with truckchasers reveal that many go cruising regularly, which may mean several times a week; consequently, when cruising activity spans several decades, the numbers of contacts can reach hundreds and in some cases, thousands. Some truckchasers have repeat encounters with truckers whereas others establish longer term relationships with them; however, the majority of contacts are onetime meetings:

Uhmm man, going back to when I first came out . . I'd say in my lifetime . . over 30 years ... probably 700 to 1,000 easily ... I'm being conservative. (truckchaser, 48)

I've had sex with 2,603 different truckers for a total of 4,347 encounters . . This makes repeat encounters of 1,744. (truckchaser, 53)

I have three categories: dates, husbands, and boyfriends . . . Dates are people I've slept with, and that's somewhere around 3,500 . . Boyfriends are people I've had some sort of a relationship with and that's probably close to around 150 ... And husbands, I've had 8. (truckchaser, 47) 
Discussions with truckchasers also reveal that active cruising may continue for decades but the intensity and frequency often slows with age. Younger truckchasers' cruising activity can be described almost as sexual bingeing.

\begin{abstract}
In my younger years, I'd go cruising nightly and I'd hook up several times a night ... I never really kept count of the situations... I wouldn't even begin to give an estimate. (truckchaser, 35)

Would try to have as many experiences as I could in a night ... Depending upon how tired I was ... how horny I was etc. . . That was in my slutty period between partners [laughs]. (truckchaser, 51)
\end{abstract}

The nature of highway locales often dictates the types of sex acts that transpire there and the corresponding levels of risk. The most common activity between truckchasers and truckers is oral sex, followed by mutual masturbation, and anal sex. More often than not, oral sex is performed by truckchasers on truckers, which provides truckers with the convenience of the release they seek without the strings that are usually associated with sex with women (whether financial or emotional) and very important (particularly for straight-identified truckers), without bringing into question their sexual identity.

They're driving for long hours... Truckers get into a rest area and some guy is there waiting with a big smile, wanting to take care of whatever arises ... It happens ... and after 2 or 3 times... they go, "Hey, you know, this isn't bad ... and it's anonymous and don't have to worry about him falling in love with me and wanting my number... and chasing me down like women will ... maybe this is okay. (truckchaser, 48)

Our initial assumption that straight-identified truckers would prefer to maintain the conventional male role during anal sex, by being the insertive partner, to preclude any questions of their straight-identification was quickly abandoned. Discussions with truckchasers revealed that some straight-identified truckers actually prefer to serve as the receptive partner because they are unable to experience this type of sex with their female partners. Furthermore, truckers also demonstrate interest in reciprocating truckchasers with oral sex.

Interviewer: Do you ever engage in anal sex with truckers?

Truckchaser: Ob yes.

Interviewer: In what percentage of your encounters do you engage in anal sex?

Truckchaser: Maybe 10\%.

Interviewer: Ten percent of encounters, and of that $10 \%$, are you the "top" or "bottom?"

Truckchaser: Top. (truckchaser, 52)

Interviewer: How common is it that truckers are interested in giving oral sex to you?

Truckchaser: I'd say out of 10 truckers, I'd say about 3 to 4 of them. (truckchaser, 33)

Sexual encounters between truckers and truckchasers are accompanied at times by the use of various substances. Truckers may drink beer or smoke marijuana in order to relax or reduce inhibition prior to sexual encounters and sometimes offer some to truckchasers. 
Sometimes truckers might have had a couple of beers before to loosen themselves up.. . Sometimes I've ran into, especially lately, some that want to smoke a little pot before or during. (truckchaser, 47)

Although prevalent drug use-mostly crystal meth-by MSM has been extensively documented (e.g., Halkitis et al., 2001), and with frequent substance use among heterosexual trucker partnerships (Apostolopoulos \& Sönmez, 2007), drug use among MSM trucker-truckchaser populations is particularly low.

The Full Picture. Safe Sex or Calculated Risk? Sex between truckers and truckchasers can be characterized, for the most part, as clandestine, anonymous, impersonal, semipublic, and potentially risky, and their underlying motives are rather complicated. As discussed earlier, various psychological factors appear to influence decisions and behaviors involving anonymous sex with multiple partners, such as hidden or ambiguous sexual identity, loneliness, depression, impulsivity, sensation- and thrillseeking, low-risk perceptions, and stress. Our discussions provide a glimpse into the motives of these men: many truckchasers demonstrated sensation-seeking behaviors, as evidenced by frequent cruising and multiple partners, and others shared feelings of deep loneliness and need for human contact to explain their sexual encounters with truckers; they also attributed similar motives to truckers.

\begin{abstract}
My most active cruising period was right after my breakup . . I I was depressed . . I wouldn't be out of my room for weeks... One of my friends picked me up and took me to a rest area and there were like five truckers . . . in one night. . . Yeah, it opened my eyes at the opportunities and that was on a Friday went to [city] and on the way back we did it again. (truckchaser, 33)
\end{abstract}

As for why truckers go with men on the road... ? The only thing I can think is that they must be lonely. (trucker, 54)

The combination of anonymous sex with multiple partners, physical restrictions, and inconsistent condom use, all warrant a close examination of potential risk for truckers and truckchasers. Discussions of safe sex yielded ambiguous attitudes and inconsistent condom-use practices, despite the real risk for STI/HIV acquisition and transmission. Infection risk was often linked to types of sex the men engaged in and their choice of partners. For example, many perceive oral sex as low risk, whereas others believe that the position taken during anal sex determines risk level-the insertive partner who ejaculates is considered to be less at risk than the receptive partner who receives bodily fluids. For some, condom-use decisions are often superficially dictated by the healthy appearance of potential partners; for others, condom use either depends on the circumstances or is not even a serious consideration:

Mostly... it's just blow jobs ... couple of times I barebacked "top" 'cause I thought it was less risky. (truckchaser, 35)

Don't know of any case where anyone has contracted HIV from oral sex... When you have had that much oral sex as I have, and you have been tested as many times as I have, and you still remain negative, I think that's some sort of estimate. (truckchaser, 37)

Interviewer: Do you prefer to use a condom when you're the "top?"

Truckchaser: Depends on the situation and the mood I guess, I mean I'm not gonna pull any punches about it ... just depends on where it is, who it is, and what's going on at the time. 
Interviewer: Do you perceive your risk to be lower when you're penetrating?

Truckchaser: I don't know, I just really never thought about it. (truckchaser, 45)

Interviewer: Do you use condoms for oral sex?

Truckchaser: Never

Interviewer: Do you use condoms for anal sex?

Truckchaser: Only if I can keep it up ... If I can't . . just don't do anal sex . . unless they want it anyway. (truckchaser, 57)

Although we did not directly interview straight-identified truckers, discussions with truckchasers who have engaged in sex with them revealed that despite their same-sex behaviors, these men do not feel particularly at risk for HIV infection-primarily because they associate HIV with gay identity rather than same-sex behavior. By the same token, many men assume that married men or at least "straight-acting" and "straight-looking" men are safe-especially compared with gay and/or effeminate men-and so do not consider condom use a priority:

I think because most straight-identified truckers prefer to sleep with married men because they figure, well, the guy's married, so he's got to be taking care of himself. (truckchaser, 33)

Sometimes when it's over they'll say... "I sure hope you haven't got anything because I'm married and don't want to take anything home to mamma." .. . Well, at that point in time, it's too late. (truckchaser, 51)

Another crucial factor in condom-use decisions is that too often straight-identified truckers have sex with other men in a completely impulsive manner. They do not carry condoms with them simply because "being prepared" might signal premeditation and trigger unwanted scrutiny for same-sex behaviors. The risk inherent in sexual encounters with truckers unwilling to grasp the need to practice safer sex is corroborated with the following comments:

Few truckers that I run into are practicing safe sex... most don't want to use a condom ... and scores and scores try to have anal intercourse and they want to do it without a condom. (truckchaser, 37)

Don't even think that truckers have an understanding of "safe sex" . . If they do, it's been my experience that they won't, for the most part, they don't practice it . . Some people will just absolutely refuse to wear a condom... Uh, in those situations you have to make a judgment call ... And my judgment was always ... that's part of the deal. (truckchaser, 45)

Several of the more experienced truckchasers, who use condoms during anonymous sexual encounters, tend to have one partner in their lives with whom they share unprotected sex as a result of a strong bond of mutual trust. Although these men may continue for many years to cruise truckers and accrue multiple anonymous partners, they convey greater awareness of the risk involved in their chosen lifestyle and describe creative ways to assure consistent condom use.

Actually, if you can eroticize using condoms, it can be even more fun, you know what I'm saying? And that's ... I read that somewhere years ago, and that's exactly what I've done... I find it very sensuous to use condoms. (truckchaser, 51) 
Regardless of some exceptions noted above and considering increasing STI/HIV rates, too many truckers and truckchasers continue to practice UAI. Upon closer examination of possible reasons, the risks inherent in "barebacking" appear to function as an aphrodisiac, much in the same way that risks of semipublic sex do:

Interviewer: What do you think of "barebacking"?

Truckchaser: I'd say it's very popular ... I enjoy sex better without protection . . . What I think is the deal with "barebacking" . . . is the fact of the riskiness of it . . I think that turns people on.

Interviewer: Kind of, in the same way semipublic sex does?

Truckchaser: Exactly. I could get caught, I could get sick, oh, you know. (truckchaser, 39)

Certainly there are some men who avoid condoms because they do not like the sensation, others who claim they are able to perform only without condoms, and still others who are tired of constantly having to use protection or even to think about it. There are many, however, who practice "barebacking" because they seek the intimacy of skin-to-skin contact. Often the loneliness and isolation felt by some, pushes them toward experiences that bring them closer to another human being, despite the attached risk. The exchange below hints at the importance of contact over the importance of protection:

Interviewer: Do you usually carry condoms?

Truckchaser: Often, but I don't make a rule about it . . I never prefer to use condoms, but I carry them in case a trucker wants it.

Interviewer: Are there any times when you suggest "Maybe we should use a condom?"

Truckchaser: No.

Interviewer: Do truckers usually carry condoms?

Truckchaser: Rarely... Maybe 30\% at most.

Interviewer: Do they usually want to use them?

Truckchaser: Rarely... I use them, if they want to.

Interviewer: Are there things about men who are interested in sex with truckers that makes them more likely to engage in risky sexual behaviors?

Truckchaser: Yes. I can only speak for myself. I'm more interested in establishing contact in a relationship with someone... And for me, establishing contact means willingness to take a risk for someone. I don't like imposing a barrier between myself and my partner. (truckchaser, 50)

Similar to issues of identity, motivation and sexual preference, risk perception and condom use are thorny matters. Although there are some broad themes that emerge from these interviews, it is difficult to generalize behaviors to the entire sexual network of truckers and truckchasers. 


\section{CONCLUSIONS}

Given the mobility of truckers, the potential role of MSM trucking populations in STI/HIV transmission represents ongoing theoretical, methodological, and epidemiological challenges. The sexual networks of gay, bisexual, and straight-identified truckers who have sex with truckchasers as well as other men acquire further significance as truckers repeatedly bridge populations (including women) and geographic regions at truck stops, highway rest areas, PSVs, and other social contexts. Findings make clear that highways also function as sexual marketplaces with increased STI/ HIV risk channels as well as a system of conduits with the potential to facilitate propagation of both risk and infection. Concurrent MSM sex partnerships have the potential to amplify risks and initial infections because they link individuals of disparate epidemiological settings, creating large connected components that function like a road network enabling pathogens to travel rapidly and efficiently to many destinations.

The sexual exchanges among truckers and truckchasers are clearly affected by stressors that characterize the trucking profession as well as spatial attributes of cruising milieux. It is within these broad milieux where risk networks are shaped, itineraries are shared, and personal and sexual identities are concealed. Sexual exchanges with potential infection risks unfold within a homophobic occupational culture that constructs and reconstructs social identities. The manner in which masculine identities are constructed within a stressful and dangerous life presents truckers with a specific repertoire of sexual opportunities and choices. It is these complex psychosocial dynamics of sexuality that make it imperative to further understand the psychosocial context of health risks in various trucking milieux.

This baseline assessment of connections between trucker MSM networks, cruising space and STI/HIV risk has two limitations. First, the hypermasculine nature of trucking made the recruitment of straight-identified truckers an elusive task. And, although the voices of these men were indirectly heard through their sex partners, their inclusion would have provided a more complete picture of the MSM trucker risk-enabling environment. Second, for the same reasons, subsequent logistical restrictions, and issues of anonymity, we were not able to collect biological specimens from the gay and bisexual truckers and truckchasers we recruited. Because of such limitations, the comprehensive delineation of the sex exchanges of truckchasers and truckers would benefit greatly from the development of an ecological framework that integrates structural (e.g., occupational stressors), spatial (e.g., trucker itinerary), network (e.g., concurrency), psychosocial (e.g., sexual compulsivity), and biological domains (STIs, BBIs). These steps can ultimately lead to the initiation of risk, infection, and transmission tracing, mapping and modeling across highway trucking routes, thereby providing the structural basis for effective risk reduction interventions. Interventions might include web-based prevention programs, which educate truckers and truckchasers' about STI/HIV risk. Online STI/HIV education is both highly feasible and promising owing to this population's extensive use of the Internet and the numbers of Web sites and chat rooms that are dedicated to their use. 


\section{REFERENCES}

Adam, B.D., Sears, A., \& Schellenberg, E.G., (2000). Accounting for unsafe sex: Interviews with men who have sex with men. Journal of Sex Research, 37(1), 24-37.

Apostolopoulos, Y., Sönmez, S., Shattell, M., Rothenberg, R. Kronenfeld, J., Miller, M. et al. (N.D.) Sexual mixing, drug exchanges, and infection risk among truckers in North America. Manuscript under review.

Apostolopoulos, Y. \& Sönmez, S. (2007). Tracing the diffusion of infectious diseases in the transport sector. In Y. Apostolopoulos \& S. Sönmez, (Eds.), Population Mobility and Infectious Disease (pp. 131-156). New York: Springer.

Apostolopoulos, Y., \& Sönmez, S. (2006). Trucker risk networks, drug use, and transmission of sexually transmitted and bloodborne infections: Preliminary findings from the first epidemiological investigation in North America. Emory University School of Medicine, Mobility and Population Health Unit, Atlanta, GA.

Apostolopoulos, Y., Sönmez, S., Shattell, M. Rothenberg, R., Weitz, R., \& Doe, J. (2010) Infection risk along U.S. highways? The case of a 'truckchaser' cruising for truckers. International Journal of Sexual Health, 22(4), 262-271.

Apostolopoulos, Y. Sönmez, S., Kronenfeld, J., \& Smith, D. (2007). Sexual networks of truckers, truckchasers, and disease risks. In G. Herdt, \& Howe, C. (Eds.), $21^{\text {st }}$ century sexualities: Contemporary issues in health, education, and rights (pp. 112-114). London: Routledge.

Apostolopoulos, Y., Sönmez, S., Smith, D., \& Kronenfeld, J. (2003). Cruising America's highways. American Sexuality, 1, 2, March.

Binson, D., Woods, W.J., Pollack, L., Paul, J. Stall, R. \& Catania, J.A. (2001). Differential HIV risk in bathhouses and public cruising areas. American Journal of Public Health, 91, 1482-86.

Centers for Disease Control and Prevention. (2003a). HIV/STD risks in young men who have sex with men who do not disclose their sexual orientation (six US cities, 1994-2000). Morbidity and Mortality Weekly Report, 52, 81-85.

Centers for Disease Control and Prevention. (2003b, July). National HIV Prevention Conference. Atlanta, GA.

Chiasson, M., Hirschfield, S., Humberstone, M., DiFilippi, J., Newstein, D., Koblin, B., et al. (2003, February). The Internet and highrisk sex among men who have sex with men. Paper at the Conference on Retrovirus and Opportunistic Infections, Boston.
Cooper, A. (Ed.) (2002). Sex and the Internet. London: Brunner-Routledge.

Delamater, J.D., \& Hyde, J.S. (1998). Essentialism vs. social constructionism in the study of human sexuality. Journal of Sex Research, $35,10-18$.

Denzin, N.K., \& Lincoln, Y.S. (Ed.). (1994). Handbook of qualitative research. Thousand Oaks, CA: Sage.

Diaz, R.M., Ayala, G., Bein, E., Henne, J., \& Marin, B.V. (2001). The impact of homophobia, poverty, and racism on the mental health of gay and bisexual Latino men: Findings from 3 US cities. American Journal of Public Health, 91, 927-932.

Emerson, R.M., Fretz, R.I., \& Shaw, L.L. (1995). Writing ethnographic fieldnotes. Chicago: University of Chicago Press.

Flowers, P., Marriott, C., \& Hart, G. (2000). "The bars, the bogs, and the bushes": The impact of locale on sexual cultures. Culture, Health \& Sexuality, 2, 69-86.

Halkitis, P.N. \& Parsons, J.T. (2003). Intentional unsafe sex (barebacking) among men who meet sexual partners on the Internet. AIDS Care, 15(3), 367-378

Halkitis, P.N., Parsons, J.T., \& Stirratt, M.J. (2001). A double epidemic: Crystal methamphetamine drug use in relation to HIV transmission among gay men. Journal of Homosexuality, 41, 17-35.

Heckathorn, D. (1997). Respondent-driven sampling: A new approach to the study of hidden populations. Social Problems, 44, 174-99.

Hollister, J. (1999). A highway rest area as a socially reproducible site. In W.L. Leap (Ed.), Public sex, gay space (pp. 55-70). New York: Columbia University Press.

Hollister, J. W. (2003). Reflections of social structure in cruising sites. Paper presented at the annual meeting of the American Sociological Association, Atlanta, Georgia.

Horvath, K.J., Bowen, A.M., \& Williams, M.L. (2006). Virtual and physical venues as contexts for HIV risk among rural men who have sex with men. Health Psychology, 25, 237-242.

Huber, J.D., \& Kleinplatz, P.J. (2002). Sexual orientation identification of men who have sex with men in public settings in Canada. Journal of Homosexuality, 42, 1-20.

Junge, B. (2002). Bareback sex, risk, and eroticism: Anthropological themes (re-)surfacing in the post-AIDS era. In E. Lewin, \& W.L. Leap (Eds.), Out in theory: The emergence of lesbian and gay anthropology. Chicago: University of Chicago Press.

Kippax, S. \& Crawford, J. (1993). Flaws and in the theory of reasoned action. In D. Terry, 
C. Gallois, \& M. McCamish (Eds.), The theory of reasoned action: Its application to AIDS-preventive behavior. Oxford, England: Pergamon.

Lichtenstein, B., Hook, E.W., Grimley, D.W., St. Lawrence, J.S. \& Bachmann, L.H. (2008). HIV risk among long-haul truckers in the USA. Culture, Health, and Sexuality 10, 43-56.

Mansergh, G., Marks, G., Colfax, G.N. Guzman, R., Rader, M., \& Buchbinder, S. (2002). "Barebacking" in a diverse sample of men who have sex with men. AIDS, 16, 653-659.

McFarlane, M., Bull, S.S., \& Rietmeijer, C.A. (2000). The Internet as a newly emerging risk environment for sexually transmitted diseases. Journal of the American Medical Association, 284, 443-446.

McKirnan, D.J., Vanable, P.V., Ostrow, D.G., \& Hope, B. (2001). Expectancies of "escape" and sexual risk among drug and alcoholinvolved gay and bisexual men. Journal of Substance Abuse, 13, 137-154.

McLelland, M.J. (2002). Virtual ethnography: Using the Internet to study gay culture in $\mathrm{Ja}$ pan. Sexualities, 5, 387-406.

Mettey, A., Crosby, R.A., DiClemente, R.J., \& Holtgrave, D.R. (2003). Associations between Internet sex seeking and STI-associated risk behaviors among men who have sex with men. Sexually Transmitted Infections, 79, 466-468.

Parsons, J.T., \& Halkitis, P.N. (2002). Sexual and drug-using practices of HIV-positive men who frequent public and commercial sex environments. AIDS Care, 14, 815-826.

Perdue, T., Thiede, H., Valleroy, L., \& MacKellar, D. (2001). Unprotected sex and the Inter- net: Is meeting place related to risk? Public Health Seattle and King County. [Retrieved May 10, 2010, from http://www.metrokc. gov/health/apu/ 2003.

Rebchook, G., Curotto, A., \& Kegeles, S. (2003). Exploring the sexual behavior and Internet use of chatroom-using men who have sex with men through qualitative and quantitative research. Paper presented at the 2003 National HIV Prevention Conference, Atlanta, GA.

Rietmeijer, C.A., Bull, S.S., McFarlane, M., Patnaik, J.L., \& Douglas, J.M. (2003). Risks and benefits of the Internet for populations at risk for STIs: Results of an STI clinic survey. Sexually Transmitted Diseases, 30, 15-19.

Somlai, A.M., Kalichman, S.C., \& Bagnall, A. (2001). HIV risk behavior among MSM in public sex environments: An ecological evaluation. AIDS Care, 13, 503-514. doi:10.1080/09540120120058030

Stratford, D., Ellerbrock, T.V., Akins, J.K., \& Hall, H.L. (2000). Highway cowboys, old hands, and Christian truckers: Risk behavior for HIV infection among long-haul truckers in Florida. Social Science and Medicine, 50, 737-49.

Valway, S., Jenison, S. Keller, N. Vega-Hernandez, J. \& Hubbard McCree, D. 2009. Risk assessment and screening for sexually transmitted infections, HIV, and hepatitis virus among long-distance truck drivers in New Mexico, 2004-2006. American Journal of Public Health, 99, 2063-2068. 
Reproduced with permission of the copyright owner. Further reproduction prohibited without permission. 